\title{
ESTRATÉGIAS E DESAFIOS PARA O USO DA LOUSA DIGITAL INTERATIVA POR MEIO DE METODOLOGIAS ATIVAS Maria da Conceição Lima Vieira ${ }^{1}$, Adja Ferreira de Andrade
}

\author{
${ }^{1}$ Instituto Metrópole Digital - Universidade Federal do Rio Grande do Norte (UFRN) \\ Av. Sen. Salgado Filho, 3000 - Lagoa Nova, CEP: 59.078-970 - Natal - RN - Brasil \\ lisarbcei@gmail.com, adja@imd.ufrn.br
}

\begin{abstract}
This article aims to discuss the insertion of educational practices, through active methodologies, using the Interactive Digital Whiteboard, considering the result of a research carried out with teachers of the Natal Municipal Network (RN), which point out difficulties in handling and unfamiliarity with the equipment. Initially, we understand the aspects that make LDI underutilized in the classroom, as it is a resource of wide digital technological disposition, capable of mobilizing the teaching in an interactive and media way. For its better use, we have designed didactic-methodological proposals that allow the insertion of this equipment in the pedagogical practice of English language teachers, as well as its insertion in the teaching plan. Therefore, we understand the importance of updating this instrument of information and communication technology and the new methodological approaches in teacher training, in order to diversify the teaching work.
\end{abstract}

Keywords: Interactive Digital Whiteboard. Active Methodologies. Teachers training

Resumo. O presente artigo tem como objetivo discutir a inserção de práticas educativas, por meio das metodologias ativas, com a utilização da Lousa Digital Interativa, considerando o resultado de uma pesquisa realizada com professores da Rede Municipal de Natal(RN), os quais apontam dificuldades de manuseio e pouca familiaridade com o equipamento. Inicialmente, compreendemos os aspectos que tornam a LDI subutilizada em sala de aula, tendo em vista ser um recurso de ampla disposição tecnológica digital, capaz de mobilizar o ensino de forma interativa e midiática. Para seu maior aproveitamento, designamos propostas didático-metodológicas que possibilitem a inserção desse equipamento no fazer pedagógico dos professores de Língua inglesa, bem como sua inserção ao plano de ensino. Para tanto, compreendemos a importância da atualização desse instrumento da tecnologia da informação e comunicação e das novas abordagens metodológicas na formação de professores, de modo a diversificar o trabalho docente.

Palavras-chaves: Lousa Digital Interativa. Metodologias Ativas. Formação de Professores.

\section{Introdução}

Frente ao desafio da inclusão das novas tecnologias da comunicação e informação para aquisição da aprendizagem, estão as escolas que caminham a passos lentos para se adequarem aos avanços da tecnologia. Elas ainda não se apropriaram dos instrumentos que facilitam a aplicabilidade da tecnologia digital, enquanto recurso metodológico para o ensino, mesmo sendo pressionadas pelos estudantes que querem, cada vez mais, a presença e a exposição dos instrumentos tecnológicos no contexto de sala de aula. 
Um dos recursos que pode ser utilizado e que une quase todas as funções presentes nos dispositivos e acesso a internet, tal qual o computador, é a Lousa Digital Interativa (LDI). A partir do seu manuseio é possível diversificar as práticas metodológicas de ensino integradas ao uso de aplicativos, jogos, redes sociais, sites de busca, maps e muitos outros recursos presentes no sistema operacional nela instalado, referendado em (Figueiredo et al, 2015).

Alguns anos atrás, LDI foram adquiridas pela Secretaria Municipal de Educação Natal e distribuídas nas unidades de ensino de suas escolas. Porém, há por parte dos docentes, dificuldades no gerenciamento das funcionalidades da LDI, pela pouca familiaridade deles com o dispositivo. Essas dificuldades interferem na preparação do planejamento didático pedagógico, com vistas a diversificar o ensino e favorecer o acesso do aluno à aulas ativas, no qual a tecnologia digital esteja presente e possibilite a aprendizagem significativa como descrito por Freire (Freire et al, 2016).

Nesse contexto, foi idealizada uma proposta de formação para os professores de Língua Inglesa através de oficinas, com o objetivo de elaborar estratégias de procedimentos metodológicos que possa colaborar com a integração das novas metodologias ao uso da LDI.

Dessa forma, tentaremos apontar práticas de ações formativas pela ação metodológica de intervenção docente para a sala de aula, agregando tecnologia e conhecimento ao desenvolvimento pedagógico dos professores, com vistas ao manuseio e uso da LDI (conhecimento técnico), da inserção das novas metodologias aos recursos tecnológicos (conhecimento didático-pedagógico), considerando que há uma necessidade da inserção dos recursos das Tecnologias da Informação e Comunicação (TICs) para que os docentes possam interpretar as novas linguagens midiáticas, tornando suas aulas mais criativas, mais dinâmicas, com o intuito de agregar os recursos digitais numa ação dialógica que intensifique os processos informacionais e comunicativos provocados pela interação/interatividade proposta no currículo escolar, de modo que incentive os estudantes a usarem a tecnologia adequadamente ao cumprirem suas tarefas escolares.

O objetivo desta formação consiste em abordar as principais funcionalidades técnicas da LDI, agregados aos recursos presentes nos aplicativos de jogos, vídeos, imagens e outros componentes midiáticos; investigar as dificuldades dos professores em utilizar a LDI; propor estratégias didático-metodológicas para o uso das ferramentas da LDI na atuação docente, como também, discutir alguns desafios a serem alcançados.

O ensino-aprendizagem é um dos caminhos viáveis para a inserção do uso das TICs na tentativa de diversificar as práticas tradicionais, sendo a LDI, de acordo com Silva e Inocêncio (2018, p.86) "um sistema de exibição interativo comumente usado em aplicações educacionais" capaz de mudar o atual cenário educativo juntamente com a abordagem das metodologias ativas.

Este trabalho está estruturado em 4 seções. A seção 1 apresenta a introdução, a seção 2 descreve a Metodologia da pesquisa, a seção 3 sugere algumas estratégias utilizando Metodologias Ativas. Finalmente, a seção 4 apresenta as considerações Finais.

\section{Metodologia}

O percurso de realização deste trabalho foi estruturado em etapas. Inicialmente uma fase exploratória, seguida de um planejamento e formulação das estratégias. Durante a fase exploratória foi investigado o porquê da subutilização da LDI pelos professores das 
unidades de ensino da rede pública Municipal de Natal. Fizemos uma pesquisa com 21 (vinte um) professores de Língua Inglesa, participantes do curso de formação continuada, promovida pela Secretaria Municipal de Educação, a fim de averiguar o seu trabalho pedagógico e suas experiências de uso das TICs, especificamente no que diz respeito a LDI. Dessa forma, analisamos as razões pelas quais esse equipamento ainda não faz parte da rotina do planejamento e do trabalho pedagógico do professor e quais os motivos de não inseri-la nas tarefas do plano de ensino.

Essa análise foi feita a partir de um questionário formulado no google forms e disponibilizada na rede social WhatsApp no grupo de professores participantes da formação continuada, aproveitando as possibilidades que as tecnologias digitais podem oferecer para o trabalho pedagógico das instituições escolares (Valença et al, 2018).

As figuras desta seção, ilustram o resultado de alguns dos questionários feitos aos professores em formação.

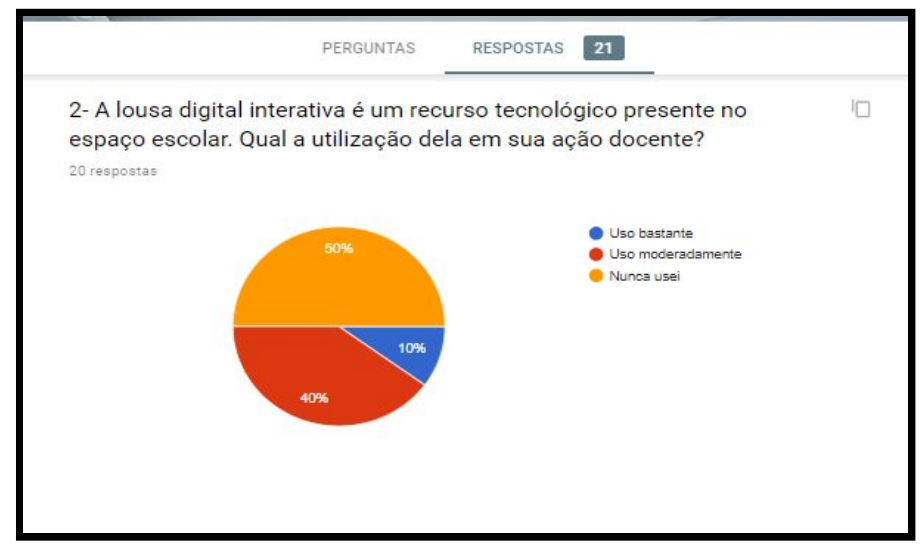

Figura 1 - Utilização da LDI na sala de aula.

O gráfico acima demonstra que apenas uma quantidade mínima de professores (10\%) usam a LDI nas aulas do componente curricular de Língua inglesa em tarefas corriqueiras de sala de aula, por sua vez, (40\% ) usam a Lousa moderadamente, enquanto a maior parcela $(50 \%)$ nunca fez uso dela em suas práticas de sala de aula.

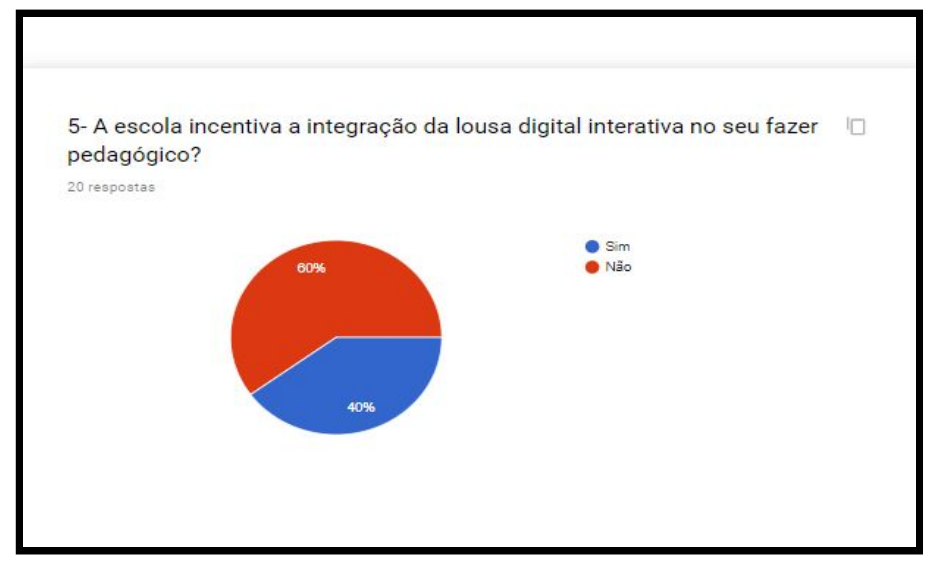

Figura 2: Incentivo ao uso da LDI

$\mathrm{Na}$ resposta da figura 2, os docentes reforçam o pouco uso da LDI. Desse modo, reconhecemos alguns motivos que provocam esse fato, descrito pelos mesmos docentes entrevistados: dificuldade de operacionar o equipamento; a instabilidade do acesso à internet; dificuldades e barreiras técnicas; perda de tempo na preparação do ambiente; 
defeito do equipamento em algumas ocasiões; falta de tempo para produzir material audiovisual; ausência de formação para utilização da LDI; insegurança e receio de não saber usar o equipamento; a não inclusão do recurso ao planejamento escolar, bem como a falta de incentivo ao seu uso. Esses motivos têm levado os professores a desprestigiarem o uso do instrumento na prática de ensino.

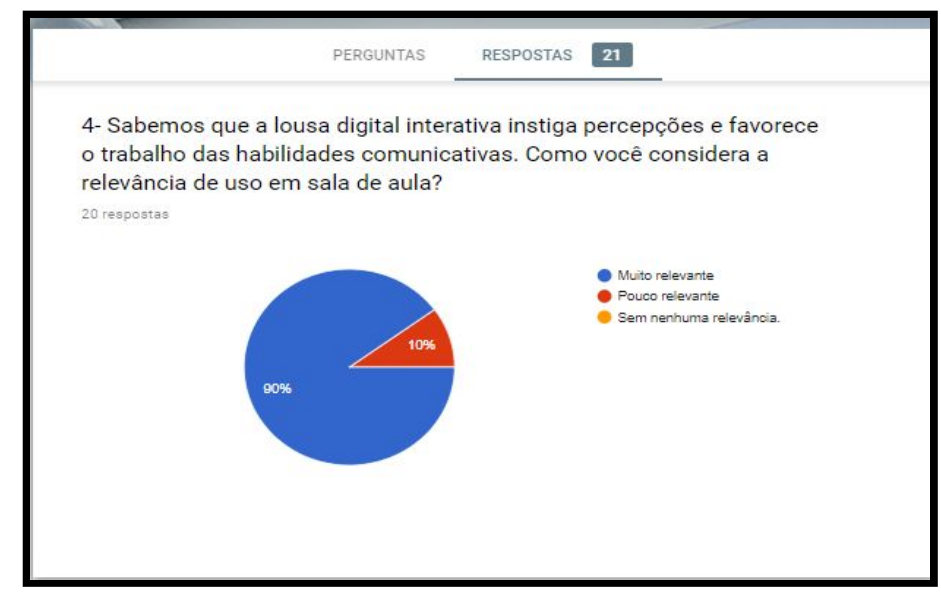

Figura 3:Relevância do uso da LDI em sala de aula

Os professores reconhecem que o instrumento é relevante para sala de aula, conforme as respostas de noventa por cento (90\%) dos entrevistados, no entanto, para outros dez por cento (10\%), a LDI não é importante para o desenvolvimento de práticas comunicativas.

No que concerne a fase de planejamento, foram executadas oficinas de formação, onde foram aplicadas estratégias de utilização da Lousa através de Metodologias Ativas. Algumas destas estratégias serão ilustradas na seção a seguir.

\section{Estratégias Metodológicas Ativas com o Uso da Lousa Digital Interativa}

As metodologias Ativas podem ser definidas enquanto modalidades de ensino que favorecem a construção da aprendizagem. Um dos pontos primordiais das metodologias ativas é combinar atividades presenciais e atividades realizadas por meio das tecnologias da informação e comunicação (TDICs). O aprendizado acontece pela antecipação de situações problemas que podem ser vivenciadas pelos estudantes nas relações corriqueiras. Esse modelo educacional, conhecido por ensino híbrido, torna a educação disruptiva e foge aos padrões convencionais de ensino com a utilização das ferramentas da tecnologia digital, as quais, propiciam uma dinâmica diferenciada tornando o aluno autônomo na prática da pesquisa e na ação colaborativa com seus pares.

As atividades desenvolvidas se mesclam entre o espaço virtual e o físico e culminam na descoberta do conhecimento. A realização de vivências pedagógicas, baseada em metodologias ativas, conforme Valente (2018), torna o aluno protagonista do seu próprio conhecimento. As metodologias Ativas se diferenciam das metodologias tradicionais por colocarem o aluno no centro do processo de ensino-aprendizagem, impulsionando-o na tomada de decisões, no desenvolvimento crítico-argumentativo, a partir dos desafios propostos. Conforme Moran et al (2015) "O ensinar e aprender acontece numa interligação simbiótica, profunda, constante entre o que chamamos mundo físico e mundo digital." 
Os estudantes, ao abstraírem o conhecimento, dialogam com seus pares, com seu professor, com o próprio conteúdo em questão, formulam suas hipóteses e, a partir das problematizações, eles são encorajados a vencer desafios por conta própria. Nesse sentido, a maturação do conhecimento ocorre mais rapidamente, pois passam a refletir e posicionar-se sobre as temáticas trazidas pelo docente, das quais buscam interpretá-las e compreendê-las, pelas leituras prévias, antes de chegar dentro da sala de aula.

O trabalho do professor, com a aplicação da metodologia ativa, instiga a interação, a reflexão e a criatividade. Ele atua como mediador, conforme Antunes et al (2018), realiza as intervenções necessárias com seus conhecimentos e experiências de ensino e incentiva os estudantes a refletirem a respeito dos seus próprios questionamentos, a fim de aprimorar o aprendizado.

Das metodologias ativas existentes, nosso trabalho apontará as seguintes abordagens: Aprendizagem Baseada em Projeto ou Project Based Learning (PBL), aprendizagem baseada em jogos ou Game Based Learning (GBL), sala de aula invertida ou flipped classroom, aprendizagem em pares ou times ou team based learning (TBL).

Essas metodologias podem se adequar ao ensino de Língua Inglesa por despertarem motivação e estímulo cognitivo aos aprendentes. Quando integradas ao recursos das TICs, proporcionam aos estudantes de uma segunda língua, não apenas o exercício das práticas das habilidades comunicativas(falar, escutar, ler e escrever), como também apresentam características positivas que podem colaborar com as novas maneiras de abstrair a aprendizagem, tais como: promover habilidades aos estudantes para processar e dar informações, compreender intuitivamente o idioma em etapas de jogos; interpretar a linguagem audiovisual presente em videoclipes do youtube; detalhar monumentos históricos e culturais pelas especificidades de imagens; identificar vocábulos e sentenças por associação e memorização com as ferramentas da galeria da LDI, dentre outros. Esses são alguns dos exemplos da combinação desse recurso interativo.

\section{1- Planejamento e Realização de Oficinas}

As oficinas foram elaboradas com o objetivo de mediar propostas de procedimentos metodológicos que possam colaborar com a integração das novas metodologias ao uso da Lousa Digital Interativa. O objetivo é possibilitar que o professor reflita, interfira como também possa sugerir outras possibilidades didáticas.

Inicialmente, foram feitas oficinas socializando as funcionalidades da LDI (calibração, disposição do teclado, uso do mouse, reconhecimento das funções das ferramentas, dentre outros).

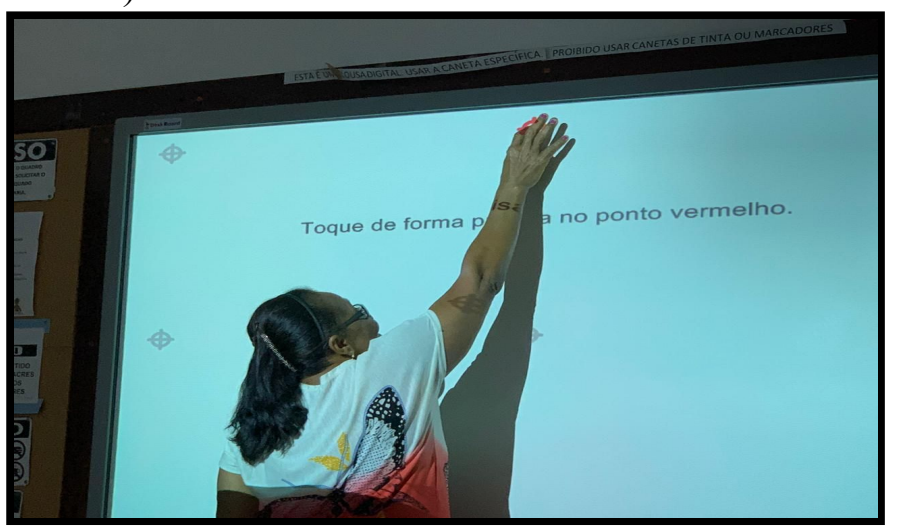

Figura 4: Oficina de uso da LDI: calibrando tela. 
Nesta fase, os professores foram convidados a manusearem a lousa, fazendo as pesquisas nas pastas de armazenamento de dispositivo externo ou da própria lousa, ou ainda, pela busca na internet.

As oficinas foram planejadas em duas etapas. No primeiro momento, o objetivo foi mostrar quais metodologias ativas serão abordadas na oficina. No segundo momento, foi realizada a demonstração de uma sequência de atividades que podem ser trabalhadas utilizando a lousa digital interativa. A tabela a seguir apresenta um quadro resumo das oficinas.

Tabela 1: Planejamento das oficinas

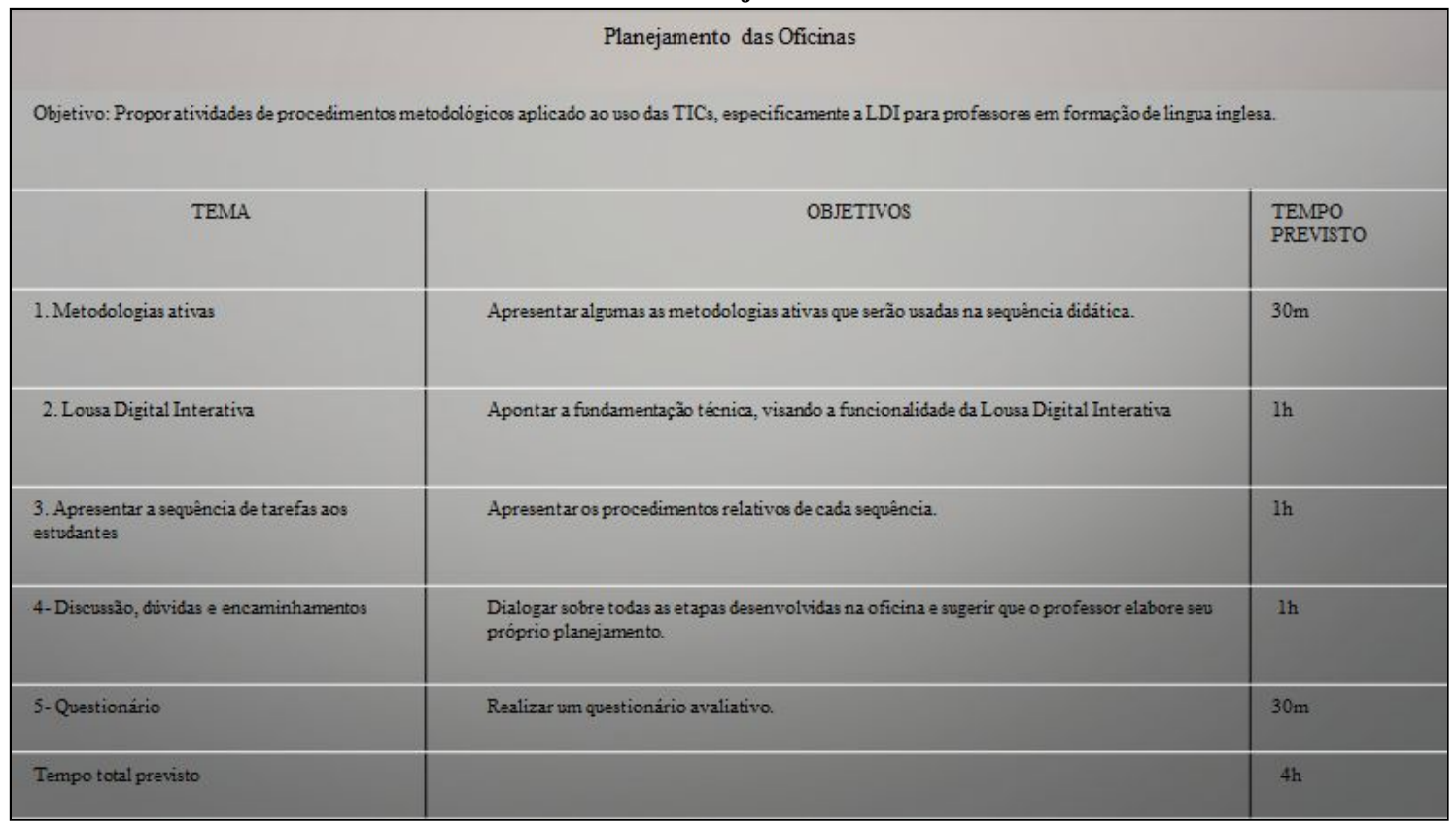

Fonte: Elaborada pela própria autora

\section{2- Estratégias Didáticas com metodologias ativas}

Nesta seção serão apresentadas algumas estratégias de trabalho possíveis de serem desenvolvidas com os estudantes, destacando procedimentos de como executar as estratégias, o tema e objetivo delas e como deve se dar a interação.

\section{Estratégia didática 1 - Aprendizagem por pares ou team based learning (TBL).}

É uma metodologia que favorece a aprendizagem pelo compartilhamento de ideias e trocas de conhecimento na perspectiva de superar desafios e obter maior desempenho na aprendizagem (Mazur, 2015).

Tema: (lixo, bullying, diversidade, drogas, ética, segurança, qualidade de vida e etc)

\section{Como fazer?}

Dividir a turma em grupos de quatro a seis componentes.

O professor apresenta, na LDI, um documentário sobre um dos temas. Essa tarefa trará uma situação problema a ser resolvida pelo aluno. Após os alunos verem o vídeo, será distribuído, com os grupos, um texto literário de todas as falas do mesmo. O texto será lido para a turma até que não se tenha nenhuma dúvida quanto a sua construção e o vocabulário nele escrito. 
$O$ professor estabelece um tempo de " $\mathrm{x}$ " minutos para que os grupos elaborem estratégias de soluções para aquele problema em questão.

Cada grupo apresenta o resultado das suas soluções utilizando alguns dos recursos da tecnologia digital. Pode ser no formato de desenho, feito na LDI, captura de imagem, vídeos ou como melhor resolverem identificar e representar. A projeção dos resultados será realizada com o recurso da LDI.

\section{Para que fazer?}

O emprego dessa tarefa, no âmbito escolar, além de facilitar o diálogo, favorece ao aluno a fixação e treino de vocabulário, de expressões e prática de leituras usando as técnicas de inferência, skimming, scanning.

\section{Como os estudantes interagem?}

A atividade favorece a elaboração de conceitos e tomada de decisões, por ser um instrumento valioso na formação de opinião quanto a solução do problema, seja ele de natureza educacional, cultural, social ou política. O resultado desenvolvido por cada estudante aprimora seu ponto de vista e sua conduta ética diante do tema apresentado.

\section{Estratégia Didática 2-Aprendizagem baseada em jogos ou Game Based Learning} $(\boldsymbol{G B L})$ Jogos são instrumentos de interação motivadores que despertam os sentidos e ativam percepções. De acordo com Carvalho (2015, p.176) "[...]é uma metodologia pedagógica que se foca na concepção, desenvolvimento, uso e aplicação de jogos na educação e na formação".

Tema: Tempos verbais e vocabulários

\section{Como fazer?}

O Kahoot é reconhecido como uma plataforma de aprendizagem baseada em jogos e pode ser usada como tecnologia educacional em escolas e outras instituições de ensino. O professor acessa a plataforma Kahoot, insere o login e senha e escolhe qual tipo de tarefa vai desenvolver com a turma. O Professor pode criar seu próprio jogo para revisar assuntos relacionados ao conteúdo trabalhado. O formato das respostas pode ser por meio de Quiz, Jumble ou Survey e ainda é possível acrescentar imagem às questões. As telas de preparação do jogo são intuitivas o suficiente para o cadastro de perguntas e respostas a serem realizadas sem nenhuma dificuldade.

\section{Pra que fazer?}

Essa estratégia promove o exercício do raciocínio, concentração, participação, engajamento, esforço, atenção, memorização, entre outros.

\section{Como os estudantes interagem?}

A leitura das perguntas é feita individualmente na tela da LDI e as respostas são realizadas individualmente pelo celular do aluno. $O$ aluno não precisa baixar o aplicativo, apenas acessá-lo pela internet e inserir o código PIN que será fornecido na tela da LDI, antes do jogo iniciar.

\section{Estratégia Didática 3: sala de aula invertida ou Flipped classroom}

Essa metodologia configura-se na inversão do processo convencional de ensino. Por meio dela, o professor orienta a pesquisa e o aluno tem contato com o conteúdo, antes mesmo de ser abordado em sala de aula. Dessa forma o conhecimento é aplicado com resolução de problemas e realização de trabalhos práticos em sala de aula.

Tema: Tecnologia, Sociedade e Comunicação: o link do século XXI 
VIII Congresso Brasileiro de Informática na Educação (CBIE 2019)

Anais dos Workshops do VIII Congresso Brasileiro de Informática na Educação (WCBIE 2019)

\section{Como fazer?}

Encaminhar uma pesquisa sobre as formas de comunicação vivenciadas pela sociedade e as mudanças ocorridas com a evolução da tecnologia digital. Os estudantes deverão fazer uma apresentação usando os seguintes recursos de elaboração própria: vídeo, powerpoint, jogos, documentário, ebook, dentre outros.

\section{Pra que fazer?}

Compreender as mudanças ocasionadas pela evolução da tecnologia digital e como as pessoas as usam na comunicação para suas necessidades cotidianamente.

\section{Como os estudantes interagem?}

Por ser um tema bastante amplo, os estudantes podem trazer diversos resultados dos quais podemos intuir as seguintes possibilidades: evolução dos meios de comunicação, uso das redes sociais, cyberbullying, consumo, mídias digitais, dentre outros. A partir dos resultados, os estudantes apresentarão suas pesquisas utilizando a LDI

\section{Estratégia Didática 4: Aprendizagem baseada em projeto ou Project Based}

Learning (PBL) A aprendizagem baseada em projeto prevê tarefas e desafios para que os estudantes dialoguem com uma problemática na tentativa de solucioná-la. Esses desafios comportam situações relacionadas à vivências corriqueiras o que torna esse ensino mais relevante para a vida dos alunos, como nos aponta Bender (2014). No decorrer das tarefas são trabalhadas habilidades e competências bem como o desenvolvimento do raciocínio crítico. Os conteúdos podem ser trabalhados interdisciplinarmente envolvendo o conhecimento específico de outros componentes curriculares, tais como: língua portuguesa, artes, ciências, matemática, dentre outros.

Tema: O silêncio da vida marinha destratado pela ação humana nesse ambiente.

\section{Como fazer?}

Pedir para que a turma comente sobre as espécies de vida marinha. Naturalmente, eles irão distinguir as diversas espécies nesse ambiente. Contaremos, assim, com uma lista de diversas espécies marinhas. O professor vai averiguar a respeito dos conhecimentos prévios dos estudantes sobre as variedades de vida marinha e dos efeitos causados a essas vidas, quanto ao descuido humano em sua ação predatória.

\section{Pra que fazer?}

Tornar os estudantes conscientes do seu papel ambiental e despertar para os danos provocados pela falta de cuidado.

\section{Como os estudantes interagem?}

Antecipadamente, identificar na galeria de imagens da LDI os animais marinhos disponíveis, seus nomes e espécies, e elaborar uma apresentação das imagens de forma colaborativa. Em seguida, dividir a turma em grupo e encaminhar uma pesquisa que possa trazer informações sobre o habitat marinho: modo de reprodução, suas formas de vida e o que acontece quando eles são submetidos ao contato com resíduos tóxicos, lixo, dejetos, entre outros. Cada grupo apresentará, na LDI, seus resultados. A coleta e apresentação desses dados trará reflexões e discussões das consequências ambientais quando o homem não executa a sua parte. A interação dos estudantes com o equipamento, no momento da apresentação, torna os fatos cada vez mais evidentes, por mostrarem imagens virtuais, embora reais, das diversas situações de vida enfrentadas por esses seres. 
VIII Congresso Brasileiro de Informática na Educação (CBIE 2019)

Anais dos Workshops do VIII Congresso Brasileiro de Informática na Educação (WCBIE 2019)

\section{Considerações Finais}

A LDI amplia as possibilidades da inserção dos recursos trazidos pela tecnologia digital dentro do ambiente de sala de aula. A utilização adequada da Lousa pode proporcionar uma melhoria na interação, nas relações de aprendizagem, aproximando o virtual e o real, na busca por conteúdos e resultados nela apresentada.

Nesse aspecto, a escola que utiliza uma Lousa Digital tem a possibilidade de criar espaços mais privilegiados para o exercício de práticas e habilidades, propensa a difundir o conhecimento pelo diálogo, com vistas a dinamizar a compreensão dos conteúdos, os quais favoreçam o ensino dinâmico, participativo e envolvente.

No entanto, e infelizmente, tal recurso não é bem aproveitado nas escolas da Rede Pública Municipal de Natal, pela dificuldade que os docentes sentem em manuseá-la, como também, de inseri-la nas suas propostas de planejamentos escolar e futuramente, na compilação de um projeto gestor para a utilização da LDI.

Dessa forma, destacamos alguns dos desafios que ainda se perpetuam, no que diz respeito à inserção da LDI no ambiente escolar. Um dos principais desafios é investir na formação continuada dos professores, na perspectiva de apresentar e interpretar a utilidade da LDI, com vistas a aprendizagem participativa, profícua e significativa dos estudantes. O que se espera é que os recursos sejam melhor utilizados, como instrumento em atividades curriculares e possam contemplar projetos que se integrem interdisciplinarmente.

Finalmente, é também um outro enfrentamento importante, remodelar o ensino tradicional para um modelo mais inovador, utilizando as tecnologias digitais da informação e comunicação, como também inserir as metodologias ativas agregadas ao uso da LDI.

\section{Referências}

ANTUNES, A.; Abreu, J.; Padilha, P. R.; (Org.). EaD freiriana [livro eletrônico]: artigos e projetos de intervenção produzidos durante o curso A escola dos meus sonhos ministrados pelo professor Moacir Gadotti. São Paulo: Instituto Paulo Freire, 2018.

BACICH, L.; Neto, A. T.; Trevisani, F. M. (Org.). Ensino híbrido: personalização e tecnologia na educação. Porto Alegre: Penso 2015.

BENDER, William. N. Aprendizagem baseada em Projetos: educação diferenciada para o Século XXI; tradução: Fernando de Siqueira Rodrigues; revisão técnica: Maria da Graça Souza Harn. - Porto Alegre: Penso, 2014.

CARVALHO, C. V. Aprendizagem Baseada em Jogos. II World Congress on Systems Engineering and Information Technology. Instituto Superior de Engenharia do Porto, November 19 - 22, 2015, Vigo, SPAIN.

FIGUEIREDO, A. M. B.; LAMAIZON M. L.; BANHARA A. F. Uso pedagógico das lousas digitais na educação básica. Anais do EDUCERE XXII Congresso Nacional de Educação. PUCPR, 2015.

FREIRE, V. P.; CARVALHO, D. B. N.; LIMA, R. D.; O uso pedagógico da lousa digital interativa no Instituto Luciano Barreto Júnior como referência nos 
VIII Congresso Brasileiro de Informática na Educação (CBIE 2019)

Anais dos Workshops do VIII Congresso Brasileiro de Informática na Educação (WCBIE 2019)

processos de ensinar e aprender. $7^{\circ}$ SIMEDUC - Simpósio Internacional de Educação e Comunicação. Unit Aracaju SE 14 a 16 de set 2016.

GOMES, A. S. et al. Cultura digital na escola: habilidades, experiências e novas práticas / Alex Sandro Gomes; Pasqueline Dantas Scaico; Lays Rosiene Alves da Silva; Ivson Henrique Bezerra dos Santos - Recife: Pipa Comunicação, 2015.

MAZUR, E. (2015). Peer instruction: a revolução da aprendizagem ativa. Tradução: Anatólio Laschuk. Porto Alegre: Penso, 2015. e-PUB [recurso eletrônico].

MORÁN, José. Mudando a educação com metodologias ativas. Coleção Mídias contemporâneas. Convergências Midiáticas, Educação e Cidadania: aproximações jovens. Vol. II. Carlos Alberto de Souza e Ofelia Elisa Torres Morales (orgs.). PG: Foca Foto-PROEX/UEPG, $2015 . \quad$ Disponível em:http://www2.eca.usp.br/moran/wp-content/uploads/2013/12/mudandomoran.pdf Acesso em: 22 set. 2019.

OLIVEIRA, Agostinho C.; Araújo, Samira M. Métodos Ativos de Aprendizagem: uma breve introdução. 2015.2 Disponível em:https://www.researchgate.net/publication/280091153_Metodos_Ativos_de_Apre ndizagem_uma_breve_introducao . Acessado em: 22 set. 2019. doi: 10.13140/RG.2.1.5004.6561

SILVA, H.; A.; Inocencio. A.; C.; G. Hoaldi - um conjunto de heurísticas para a avaliação e desenvolvimento de Objetos de Aprendizagem para Lousa Digital Interativa. In Congresso Brasileiro de Informática na Educação (CBIE 2018). p. 85-89 Anais (online) do Workshop do VII Congresso Brasileiro de Informática na Educação (WCBIE 2018). Acesso em: 29 set. 2019

VALENÇA, C. C. B. A. et al. O uso de ferramentas digitais de comunicação como recurso para o planejamento colaborativo e interdisciplinar docente. In: Congresso Brasileiro de Informática da Educação, 29 de outubro a 01 de novembro de 2018. Anais (online) do XXIV WIE - Workshop de Informática na Educação. p.529-538. Fortaleza-CE: $\quad$ WIE, $2018 . \quad$ Disponível em: http://dx.doi.org/10.5753/cbie.wie.2018.529. Acesso em: 28 set. 2019.

VALENTE, José Armando. A sala de aula invertida e a possibilidade do ensino personalizado: uma experiência com a graduação em midialogia. In: BACICH, Lilian; MORAN, José. Metodologias ativas para uma educação inovadora: uma abordagem teórico-prática. Porto Alegre: Editora Penso, 2018. 